\section{Random fingers}

Sir-Edwards (Nature 246, 419; 1990) points out the subjective element of describing a pattern, which raises an interesting practical problem in the use by police forces and others of fingerprints as a method of identification. Modern technology now offers the possibility of automatically searching large collections of fingerprints, with considerable benefits in time saved in making identifications.

The economical storage and transmission of fingerprint images requires electronic processing, during which some of the information contained in the original image is necessarily lost. At some point, depending on the extent of this processing, so much information is lost that the processed image can no longer be said to resemble the original. The point at which this occurs is perceived differently by expert fingerprint officers and nonexperts; the former are far more discerning and can identify very small differences.

The nature of a fingerprint image makes it especially sensitive to information loss from key areas, which makes simple comparisons of correctly and incorrectly recorded pixels useless as measures of information loss. An objective way of measuring the information content and hence information loss from fingerprint images would be of considerable value in the design and evaluation of automatic fingerprint identification systems.

A. HOLT

Police National Computer Organisation, Home Office,

Horseferry House,

Dean Ryle Street,

London SW1P 2AW, UK

\section{Polarized views}

SIR-Derek Fordham in his review of the Navigation Foundation's report Robert E. Peary at the North Pole (Nature 344, 902; 1990 ) asserts that it contains no new information, only new analysis. We did indeed report little new information but identified a need for competent analysis. For example, we confirmed Will Steger's duplication of Peary's mileages, discredited by Wally Herbert, by correlating satellite location data with daily log entries, verified by Steger. Our use of Peary's depth soundings to show by current bathymetric data that he was on track to the Pole, was a first.

Also unique was our application of photogrammetry to Peary's photographs. When Fordham says our shadow analysis suffers from uncertainties of time of day at which the pictures were taken, he overlooks our determination of approximate times derived from analysis of the pictures together with Peary's captions. There is a unique characteristic of the Sun's diurnal path at the poles independent of date or time. At latitudes a degree or more less than 90 degrees the path is inclined so that solar altitudes measured approximately 16 hours apart, as in this case, differ by an order of a degree or more, because the difference will depend on the latitude and the change in declination. By contrast, the difference at the Pole is quite small, being only the changed declination, about one quarter of a degree.

We have now published a supplement to our report which contains two pictures, each showing both the Sun and the horizon, thus permitting direct measurement of the Sun's altitude. These altitudes agreed to within one-tenth of a degree with those from the shadow analysis, enabling us to show the altitude change was only that expected due to changing declination, and therefore that the pictures had been taken at or very near the pole.

The Navigation Foundation,

T. D. DAVIES

PO Box 1126, Rockville,

Maryland 20850, USA

FORDHAM REPLIES - In view of all the evidence available, some of it in the Navigation Foundation's own report, and the points I made in my review, I remain unconvinced by the new information. Further, the mileages achieved on Will Steger's expedition do not confirm Peary's. On the last stages to the pole, from the latitude where, on Peary's expedition, Bartlett turned back, Steger achieved a daily average of 18.8 nautical miles per day latitude distance whereas Peary claimed 26.

The bathymetric analysis relies on a small-scale computer-generated oceanfloor map on which it is impossible to be as precise as the Navigation Foundation would wish. It can be interpreted to support either case. The foundation's report confirms uncertainties as to the time when Peary's polar photographs were taken. Accurate time is the essence of positionfinding navigation and cannot be derived from examining photographs whose exact bearings are unknown.

At the pole, the Sun appears above the horizon in mid-March and rises in an ascending spiral to an altutide of approximately $23^{\circ} 30^{\prime}$ on about 22 June. It is only on that date, by which time Peary had been back on board his ship for 2 months, that the Sun followed the almost level course Davies describes above the Pole. In no way is the Sun's path, at the pole or anywhere else, "independent of date or time".

In fact, on 6 April 1909, when Peary claimed to be at the pole, the vertical component of the Sun's angle of ascent was greater than average and amounted to approximately $23^{\prime}$ per day. This is why it is necessary to know the exact time before attempting to use such photographs for position fixing. In the 18 -hour period during which the foundation assesses the polar photographs to have been taken, the altitude of the Sun would have changed by a minimum of $17^{\prime}$ which, if ignored, would give an error of up to 17 nautical miles in any position line based on an assumption of constant altitude.

I believe that the application of a very precise photogrammetric technique to photographs for which no similar precision in time or bearing is available cannot produce a result of sufficient accuracy to confirm Peary's presence at the pole. One degree out in the calculation of the Sun's altitude from lines drawn through estimated horizons or from objects to shadows could vary the position line by 60 nautical miles. Together with all the other uncertainties which still surround Peary's claim, such a variation could have placed him just about where Herbert claims he was on 6 April 1909.

66 Ashburnham Grove,

DEREK FORDHAM

Greenwich,

London SE10 8UJ, UK

\section{Long tree-rings}

SIR - The 1,500-year tree-ring reconstruction of Fennoscandian temperature is actually not the "longest annually resolved climate reconstruction from tree-rings yet published", as claimed in ref. 1 , but is surpassed by the 1,614-year tree-ring reconstruction of the Palmer drought index for North Carolina ${ }^{2}$. These two reconstructions can claim bragging rights as the longest annual tree-ring reconstructions so far produced, but much longer, absolutely dated tree-ring chronologies exist and are sure to provide millennia-long palaeoclimate reconstructions in the near future.

David W. Stahle

MALCOLM K. CLEAVELAND JOHN G. HEHR

Department of Geography,

University of Arkansas,

Fayetteville,

Arkansas 72701, USA

Climate Research Unit,

KEITH R. BRIFFA

University of East Anglia,

Norwich NR4 7TJ, UK

1. Briffa, K.R., Bartholin, T.S., Eckstein, D. Jones, P.D Karlén, W., Schweingruber, F.H. \& Zetterberg, P. Nature 346, 434-439 (1990)

. Stahle, D.W. Cleaveland, M.K. \& Hehr, J G Science $\mathbf{2 4 0}$ 1517-1519 (1988).

\section{Scientific Correspondence}

Scientific Correspondence is intended to provide a forum in which readers may raise points of a scientific character. They need not arise out of anything published in Nature. In any case, priority will be given to letters of fewer than 500 words and five references. 